K.M. Vasyliv

\title{
REGULARITIES OF ELECTROMAGNETIC PROCESSES OF A CONTACTLESS EXCITATION SYSTEM OF AN ASYNCHRONIZED GENERATOR BASED ON A CASCADE THREE-PHASE-THREE-PHASE VOLTAGE MODULATOR IN A SINGLE-STAR CIRCUIT
}

The regularities of electromagnetic processes occurring in a noncontact excitation system of an asynchronized generator based on a cascade three-phase - three-phase voltage modulator in a single-star circuit for the possibility of expanding the range of a two-zone slip of a generator are established. A method for correcting the parameters of the machines' rotors of modulator and generator is proposed which makes it possible to stabilize the operation of the switch for the slip range from minus one to plus five tenths with maintaining the performance of the asynchronized generator. References 3 , figures 8 .

Key words: asynchronized generator, voltage modulator, switch, contactless excitation system, slip.

Установлено закономерности электромагнитных процессов, протекающих в бесконтактной системе возбуждения асинхронизированного генератора на базе каскадного трехфазно-трехфазного модулятора напряжения по схеме в одну звезду на предмет возможности расширения диапазона двухзонного скольжения генератора. Предложено способ корректировки параметров роторов машин модулятора и генератора, позволяющий стабилизировать работу коммутатора для диапазона скольжения от минус единицы до плюс пяти десятых с сохранением работоспособности асинхронизированного генератора. Библ. 3 , рис. 8.

Ключевые слова: асинхронизированный генератор, модулятор напряжения, коммутатор, бесконтактная система возбуждения, скольжение.

Introduction. The basic structural elements of the current stationary power systems are thermal and nuclear power plants. At the same time, it is practicable to use a fairly large number of different autonomous electric power plants (AEPPs), both in industry and in other sectors, in particular, in transport and agricultural complex. There is a need for AEPPs also at the trenches of transport of organic energy (oil and gas pipelines). Promising is the use of wind power plants which can work in parallel with the stationary power system, and in the autonomous mode. At the moment, AEPPs have become a significant part of the generation and consumption of electrical energy in general. Therefore, attention to them, from the point of view of scientific research both in the theoretical and practical aspects in order to improve them, is sufficiently argued and logical.

For consumers of electrical energy, it is necessary to have not only reliable power supply, but also to receive high-quality electric power, one of the most important indications of which is the frequency of voltage. The stability of the voltage frequency is principally unnecessary both for stationary power systems and for autonomous power supply sources (APSS) because reducing the frequency of voltage in stationary power systems leads to loss of stability of their work and, consequently, to collapse.

For APSS, certain features are characteristic of the most significant of which it is logical to include such. The first is the probability of the necessity of operation in the mode of limiting loads which makes an actual problem of the reliability of their operation in general. The second peculiarity of such installations is the substantial volatility and wide range of changes in the frequency of the rotation of the drive of the autonomous generator, for example, wind turbine installations (WTI), which causes another problem of the volatility of the voltage frequency.
The analysis of scientific literature and practical solutions shows that these complex and actual problems can be effectively solved by the use in the APSS of asynchronized generators (ASGs) with contactless valve excitation system (CLVES) based on a cascade voltage modulator (CVM) [3]. From the point of view of the circuit decision, asynchronous generators with CLVES based on CVM can be implemented in many variants (of the order of 16 circuits). All such generators operate according to the same principle but each circuit decision of the electric circuit of the modulator, the switch and the generator itself introduces its specific features from the point of view of the physics of processes. Therefore, in scientific research, it is necessary to analyze each of these circuits separately. Proceeding from this, the object of the study in the paper is the contactless valve system of excitation of the asynchronized generator on the basis of a cascade three-phase three-phase voltage modulator (C T$\mathrm{T}$ VM) according to the circuit of single star. The circuit of a power electric circuit of such a system of excitation is shown in Fig. 1. From this figure it can be seen that C T-T VM consists of two asynchronous machines AM1 and AM2, phase windings of which rotors are split into three branches and are interconnected one-to-one by intersecting bonds, and at the input split phase segments can have a potential combined connection or can be connected to a single joint node. The options of these connections are determined by the positions of the key $\mathrm{K}$. When the key $\mathrm{K}$ is open (identifying its state as $\mathrm{K}=1$ ) this is the first option, and when the key $\mathrm{K}$ is locked $(\mathrm{K}=2)$ this is the second one. Stator windings of modulator machines AM1 and AM2 are powered by two three-phase power sources E1 and E2 which have a mutually opposite sequence of phases. Here it is a priori assumed that such sources are accumulator batteries with controlled voltage inverters. 


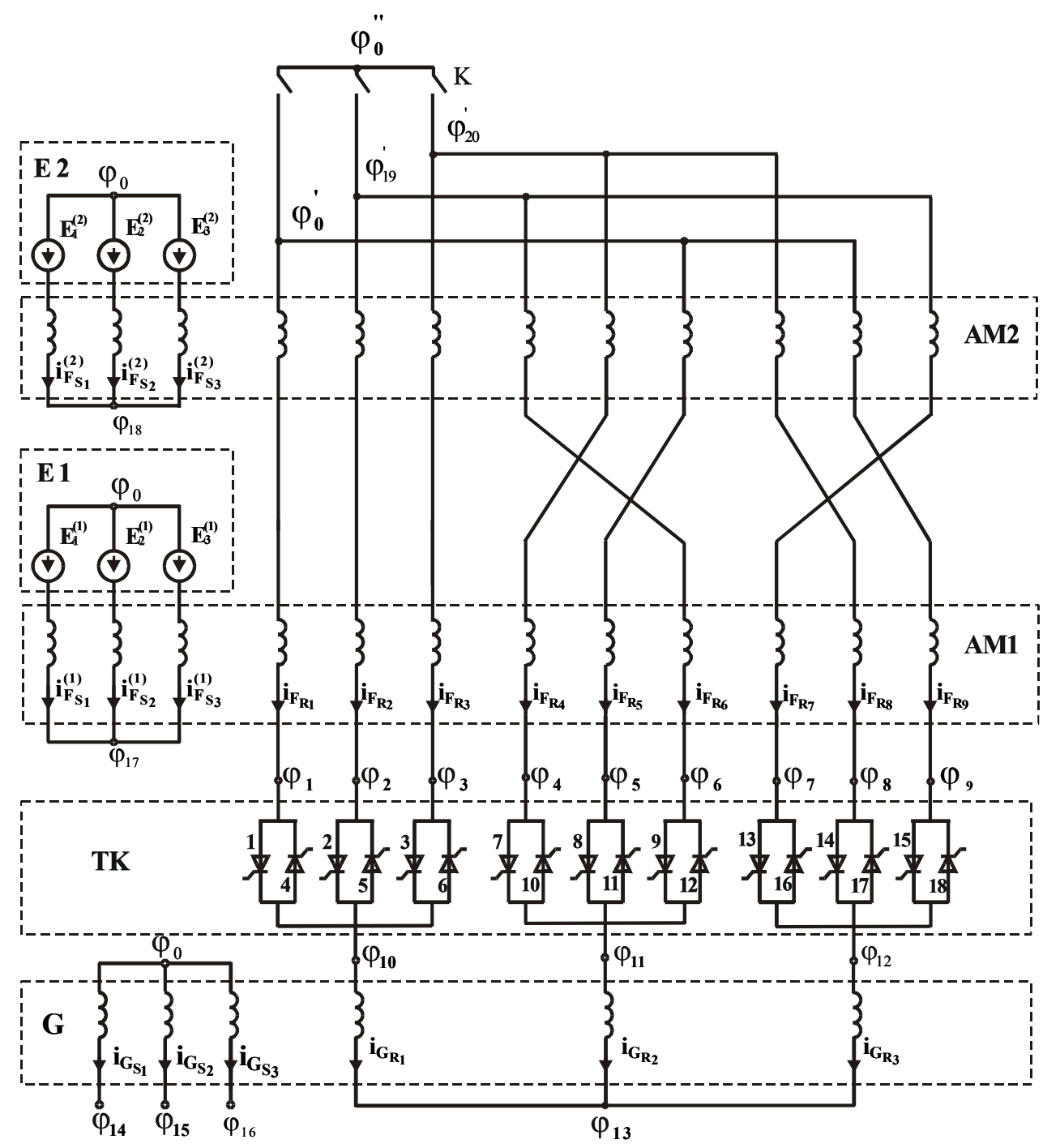

Fig. 1. Power electric circuit of asynchronized generator

The rest of the structural elements of the circuit (Fig. 1) include: TK $-a$ thyristor switch of a cycloconverter type with natural switching as which a direct thyristor frequency converter (DTFC) serves, G asynchronized generator as which as a three-phase asynchronous machine with a phase rotor, the coils of which the rotor phases are connected in a star serves. All other indications on this circuit are generally accepted: by the letters $E, \varphi$ and $i$ the electromotive forces, the electric potentials in the nodes, and the currents of the electric circuit branches are indicated. By the letters $F, G$ in the lower indices the affiliation of the coordinates (of currents, voltages, etc.) to the modulator machines and ASG are indicated, and by the letters $S, R$ in the lower indices $i$ the affiliation of the coordinates to stator and rotor of electric machines are indicated, respectively. Thyristors of DTFC are numbered. Numbers 1 and 2 in brackets in the upper indices indicate the relevance to the first E1 and the second E2 sources, respectively.

In the opinion of the author, in order to facilitate the adoption of the main provisions of the paper, it is logical to briefly describe the principle of the operation of the ASG of this type. It is based on the fact that the voltage modulator by the way of adding the voltages and frequencies of the phase branches of the rotors of the machines of the modulator forms the total voltage of the modulus form, the filling frequency of which is proportional to the frequency of rotation of the rotors of the modulator machines and the number of their pairs of poles (rotors of AM1 and AM2 are placed on one shaft with ASG), and the modulation frequency is determined by the frequency of two-zone slip. The linearly coupled winding of the rotors of the modulator, the cycloconverter type switch decodes the modulated voltage resulting in the formation of a three-phase system at its output (on the winding of the generator's rotor) slip times. This provides a stable time for rotating the magnetic field of the generator in relation to its stator winding, which, in turn, forms the frequency of the generator voltage which is equal to the frequency of the supply networks of E1 and E2. Thus, theoretically, the frequency of the ASG voltage should be equal to the frequency of the supply networks of E1 and E2 of the asynchronous machines of the modulator AM1 and AM2 and not to depend on the rotational speed of the ASG rotor.

Analysis of publications and the goal of investigations. The ideology of generators of a stable frequency (GSF) with a contactless valve excitation system based on the CVM was introduced in [3]. On the coincidence of the issues on scientific research and 
development of automotive electrical power systems (AEPS) on the basis of ASG with CLVES a rather narrow circle of scientists and engineers is working, and therefore the essential share of publications aimed at researching these systems of power supply through mathematical modeling belongs to the author of this paper. The appearance of a number of publications aimed at the development of methods and mathematical models as well as the study of the laws of the course of electromagnetic and electromechanical processes occurring in the above-mentioned AEPS is due to the presence in them of various types of elements asynchronous machines and DTFC on a number of circuits of their power electrically circles as well as the presence of a control system of the switch and automatic control system of individual coordinates (in particular, voltage) which causes the complexity of electromagnetic and electromechanical processes which occur in these AEPSs.

One of the main scientific works related to the research of the AEPS on the basis of ASG with CLVES is the publication [1]. It is aimed at the development of mathematical models and corresponding software complexes as a means for studying the regularities of the flow of electromagnetic and electromechanical processes occurring in AEPS on the basis of ASG with CLVES in three-phase - three-phase circuit of the voltage modulator. Mathematical models and corresponding software complexes allow to study electromagnetic and electromechanical processes that occur in the autonominal system of electric power supply during operation of ASG on typical load such as asynchronous motors, active-inductive and active-inductive-capacitive loads.

In the publications which are the researches of electromagnetic and electromechanical processes in the AEPS on the basis of ASG with CLVES, it is considered that asynchronous machines of the voltage modulator and the generator have a typical design. Proceeding from this, the two-zone slip diapason which ensures the normal operation of the AEPS is $\mathrm{S}=-0.06 \div+0.06$. This indicates that in general, AEPS on the basis of ASG with CLVES is operational. But such a range of slip is being developed too narrowly to argue about the feasibility of practical application of such asynchronous generators in the AEPS. Therefore, the research proceeds with the goal of achieving the expansion of the slip diapason to the limits that would allow the practical use of this class of ASG, even in such electric power plants as WTI.

Taking into account the fact that the performance of ASG with CLVES is largely determined by the proper operation of the switch, all attention should be concentrated on the processes occurring precisely in the CLVES and its separate structural elements which include the modulator machines, the thyristor switch itself and the excitation winding of the ASG (its rotor winding).

The first piece aimed at solving this problem was the publication [2] concerning the contactless excitation system of ASG on the basis of a cascade three-phase three-phase voltage modulator in the circuit of two stars (when each of the phases of the rotor winding of the generator is split into two branches, and the 6 branches thus formed are connected in two separate three-phase stars). In [2] one modulator circuit is considered in which split phases of rotors of machines of the modulator on the input are connected to a single joint node (for the circuit of Fig. 1 this is $\mathrm{K}=2$ ). According to the research [2], it was suggested that the slip range may be expanded from $\mathrm{S}=-0.06$ to $\mathrm{S}=+0.2$ by increasing the ratio of the number of turns of the stator winding to the number of turns of the rotor winding of the modulator machines.

Taking into account the specificity of each of the circuits of the thyristor switch and modulator, it is clearly evident that the practical need to perform a similar study of the contactless switch excitation system of the ASG on the basis of a three-phase - three-phase cascade voltage modulator according to the circuit of single star which is characterized by a doubly smaller number of thyristors than a two-star circuit which qualifies as an advantage in terms of practical application.

Thus, the purpose of the study is to establish the laws of the course of electromagnetic processes that occur in the contactless valve system of excitation of ASG on the basis of a cascade three-phase - three-phase voltage modulator in the circuit of single star for the possibility of expanding the working range of dual-zone slip.

Presentation of main material. The results of preliminary investigations $[1,2]$ indicate that the operation of the switch is significantly determined by the ratio of the parameters of windings of stators and rotors of the modulator machines. The huge values of the parameters of the rotors causes the inertia of the electromagnetic processes in the circuit of the modulator and generator exciter which results in disturbed normal operation of the switch which does not permit to form the three-phase voltage of the slip frequency in the winding of the rotor of the generator, and therefore, to form the voltage of the stable frequency in the stator winding of the ASG.

In order to create favorable conditions for the operation of the switch based on the positive result of the investigation obtained in [2], it is proposed to reduce the inductive resistances of rotor windings not only of the modulator machines but also of the generator by increasing the ratio between the number of turns of the stator and rotor windings (that is, an increase in their coefficients of transformation). The verification of the effect of changing the coefficients of the transformermass on the efficiency of the CLVES of the asynchronized generator is made by analyzing the functions of the currents and voltages of the phase branches of the rotors of the modulator and generator machines. The dependences of currents and voltages are obtained by calculating the electromagnetic processes of the CLVES of Fig. 1 using the mathematical model and software developed in [1]. Simulation is used for ASG of $100 \mathrm{~kW}$ power, the input data of which have the following values: $\mathrm{L}_{\mathrm{G}_{\mathrm{m}}}=0.1 \mathrm{H}$ - the operating inductance (from the stator side); $\mathrm{L}_{\mathrm{GS}}=0.005 \mathrm{H}$ - the inductance of scattering of the stator; $\mathrm{L}_{\mathrm{G}_{\mathrm{R}}}=0.005 \mathrm{H}$ - the reduced to the stator winding inductance of scattering of the winding of the rotor; $\mathrm{K}_{\mathrm{G}_{\mathrm{i}}}=10$ - the coefficient of transformation of the generator; $\mathrm{P}_{\mathrm{G}_{0}}=2$ - the number of pairs of poles of 
the generator; $\mathrm{R}_{\mathrm{GS}}=0.01 \Omega-$ the active resistance of the phases of the stator winding; $\mathrm{R}_{\mathrm{G}_{\mathrm{R}}}=0.05 \Omega$ - the active resistance of the rotor winding phases.

In order to avoid overloading the volume of input data, for modulator machines we present only the most important data, which include: $\mathrm{K}_{\mathrm{i}}^{(1)}=20$ - the coefficient of transformation of $\mathrm{AM} 1 ; \mathrm{P}_{0}^{(1)}=2$ - the number of pairs of poles of AM1; $\mathrm{K}_{\mathrm{i}}^{(2)}=20-$ the coefficient of transformation of $\mathrm{AM} 2 ; \mathrm{P}_{0}^{(2)}=6$ - the number of pairs of pole of AM2.

It is fundamentally important to note that, in accordance with the theory of ASG with CLVES on the basis of a cascade voltage modulator [3], to form the modulated voltage of the slip frequency at the output of the modulator, the ratio of the number of pairs of poles of the generator and the modulator machines must satisfy the following condition:

$$
\left(\mathrm{P}_{0}^{(1)}+\mathrm{P}_{0}^{(2)}\right) / 2=2 \cdot \mathrm{P}_{\mathrm{G}_{0}} .
$$

The above numerical values of the number of pairs of poles of the generator and the asynchronous machines of the modulator AM1 and AM2 satisfy the condition (1).

According to [2], the maximum slip value at which it was possible to achieve the performance of ASG with CLVES on the basis of CVM is 0.2 $(\mathrm{S}=+0.2)$. Therefore, for a benchmark to study the operation of ASG with a contactless valve system of excitation according to the circuit into a single star, we take precisely this value of slip. Proceeding from this, at the beginning of the study, we consider the calculating dependences of the voltages and currents of the phase branches of the rotor windings of the modulator machine and the phase currents of the rotor winding of the generator for two values of the doublezone slip $\mathrm{S}=-0.2$ and $\mathrm{S}=+0.2$.

Fig. 2 shows the calculated dependences on e time of voltages of the phase branches of modulator machine rotors.

In particular, Fig. 2, $a$ illustrates the voltages of the first three split phase branches of the rotors of the modulator machines $\mathrm{u}_{\mathrm{F}_{\mathrm{R}}}, \mathrm{u}_{\mathrm{F}_{\mathrm{R}}}, \mathrm{u}_{\mathrm{F}_{\mathrm{R}}}$ (see Fig. 1). Each of these curves is formed by the sum of the electromotive forces of the interconnected split phase branches of the machine rotors of the modulator AM1 and AM2 which, in turn, are induced separately for each of machines AM1 and AM2 by winding currents of their stators. Similarly, Fig. 2,b illustrates the voltages $\mathrm{u}_{\mathrm{F}_{4}}, \mathrm{u}_{\mathrm{F}_{\mathrm{R}} 5}, \mathrm{u}_{\mathrm{F}_{\mathrm{R} 6}}$ of the second three, and Fig. 2,c - the voltages $\mathrm{u}_{\mathrm{F}_{\mathrm{R} 7}}, \mathrm{u}_{\mathrm{F}_{\mathrm{R}}}, \mathrm{u}_{\mathrm{F}_{\mathrm{R} 9}}$ of the third three split phase branches of the rotors of the modulator machines (Fig. 1).

From Fig. 2 it can be seen that the voltages of the successively connected phase branches of the rotors of the cascade modulator machines have a modulated form with a sliding frequency (here the slip is $\mathrm{S}=+0.2$ ) which corresponds to the period $T=0.1 \mathrm{~s}$. At the same time, each of the three voltage systems, depicted in Fig. 2, $a-c$ are shifted in phase by a $2 \pi / 3$ angle over the slip frequency which is achieved by cross-connecting the split phase branches of the modulator machines (see Fig. 1). Modulated voltages with the slip frequency give reason to expect the formation of a system of three-phase voltages of the slip frequency in the rotor winding of the generator. The fact of the mutual displacement of the voltages of all three groups of phase branches with a slip frequency of $2 \pi / 3$ provides an appropriate shift of phase voltages and currents of the rotor winding of the generator.

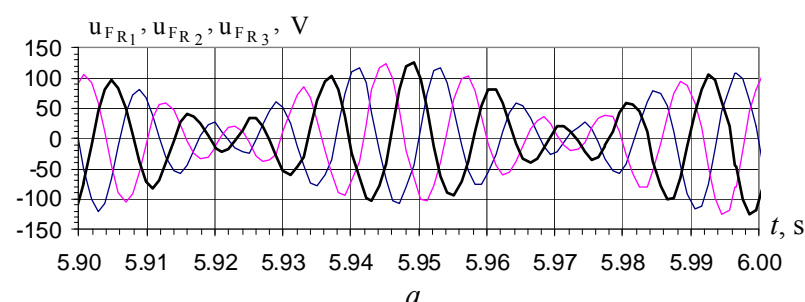

( $\mathrm{u}_{\mathrm{F}_{1}}, \mathrm{u}_{\mathrm{F}_{\mathrm{R}}}, \mathrm{u}_{\mathrm{F}_{\mathrm{R}}}$ - the voltages of I, II, III phase branches)

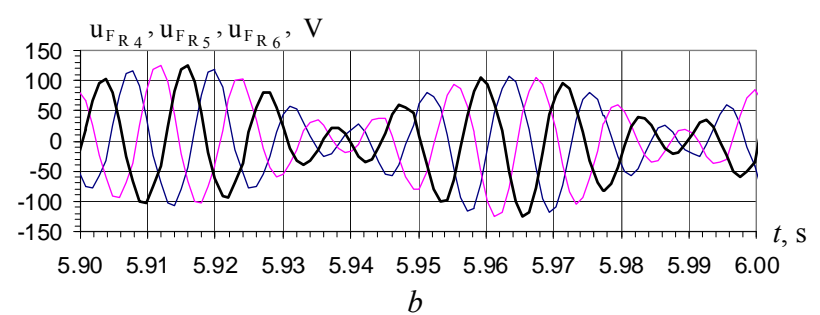

$\left(\mathrm{u}_{\mathrm{F}_{4}}, \mathrm{u}_{\mathrm{F} 5}, \mathrm{u}_{\mathrm{F}_{\mathrm{R}_{6}}}\right.$ - the voltages of IV, V, VI phase branches)

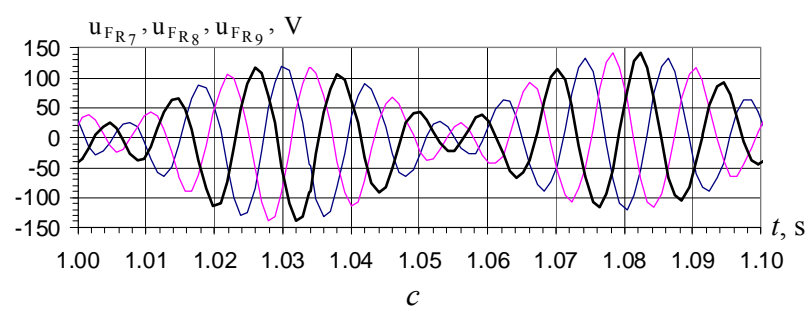

$\left(\mathrm{u}_{\mathrm{F}_{\mathrm{R}}}, \mathrm{u}_{\mathrm{F}_{\mathrm{R} 8}}, \mathrm{u}_{\mathrm{F}_{\mathrm{R} 9}}\right.$ - the voltages of VII, VIII, IX phase branches)

Fig. 2. Calculated dependencies on time of instantaneous voltages of the phase branches of the rotors of the modulator machines

For a more complete understanding of the electromagnetic processes occurring in the ASG excitation system, consider the curves of the instantaneous values of the phase currents of the rotors of the modulator machines. They are pictured in Fig. 3.

A positive half-wave of currents in Fig. $3, a$ is formed by thyristors $1,2,3$, and negative - by thyristors 4, 5, 6 (see the circuit in Fig. 1). Similarly, the currents of two other groups of phase branches of the Fig. $3, b$ and Fig, 3,c are formed, respectively.

In the context of the analysis of the processes occurring in the CLVES of the ASG, the essential characteristic of the phase voltages and currents of the generator rotor windings is of crucial importance because in order to obtain a stable voltage frequency of the winding of the stator of the generator, in the generator rotor winding there should be a three-phase system of currents of slip frequency. Therefore, consider the phase currents of the winding of the rotor of the ASG. 


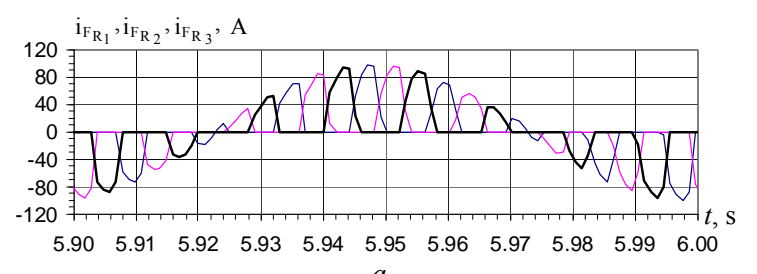

a

$\left(\mathrm{i}_{\mathrm{F}_{\mathrm{R}}}, \mathrm{i}_{\mathrm{F}_{\mathrm{R}}}, \mathrm{i}_{\mathrm{F}_{\mathrm{R}}}\right.$ - the currents of I, II, III phase branches)

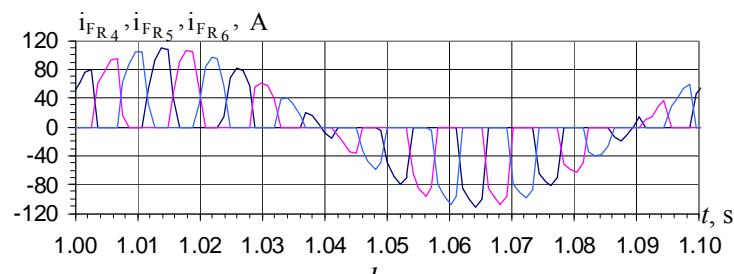

$\left(\mathrm{i}_{\mathrm{G}_{\mathrm{R}}}, \mathrm{i}_{\mathrm{G}_{\mathrm{R}}}, \mathrm{i}_{\mathrm{G}_{\mathrm{R}_{6}}}\right.$ - the currents of IV, V, VI phase branches)

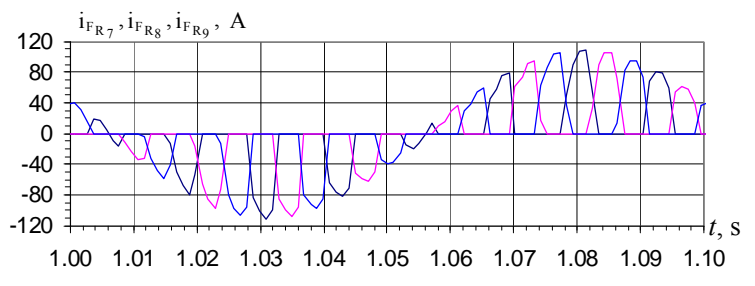

$\left(\mathrm{i}_{\mathrm{G}_{\mathrm{R}}}, \mathrm{i}_{\mathrm{G}_{\mathrm{R} 8}}, \mathrm{i}_{\mathrm{G}_{\mathrm{R} 9}}\right.$ - the currents of VII, VIII, IX phase branches)

Fig. 3. Calculated dependencies on time of instantaneous currents of the phase branches of the rotors of the modulator machines

Fig. 4 depicts the calculated dependences of the instantaneous values of the phase currents of the rotor winding of the asynchronized generator for slip $\mathrm{S}=+0.2$. From this figure it is clear that three-phase currents are formed in the winding of the ASG rotor, the shape of which is close to the sinusoidal with slip frequency. The period of these currents corresponds the slip frequency $(\mathrm{S}=+0.2)$ and is $T=0.1 \mathrm{~s}$. This shape of currents in the winding of the ASG rotor gives rise to the expectation that the frequency of the phase voltages of the stator winding will be equal to the voltage frequency in the stator windings of the modulator machines.

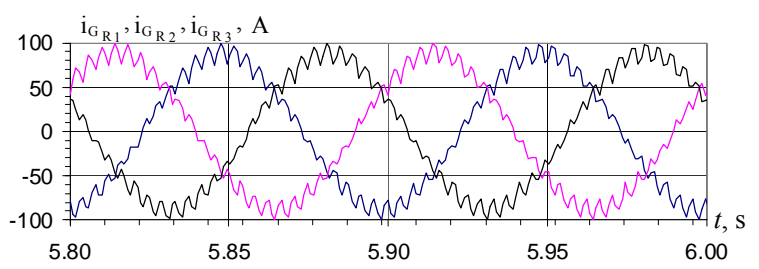

Fig. 4. Calculated dependencies of the ASG rotor phase currents

$$
\mathrm{i}_{\mathrm{G}_{\mathrm{R}}}, \mathrm{i}_{\mathrm{G}_{\mathrm{R} 2}}, \mathrm{i}_{\mathrm{G}_{\mathrm{R}_{3}}}
$$

The above simulation results, as well as the results of research which are not presented here, give grounds to assert that for ASG slip which is equal to plus two tenths $(\mathrm{S}=+0.2)$, its CLVES is operational and provides the necessary frequency of the winding voltage of the stator of the generator which is the subject of research in this publication. And the analysis of the voltage curves of the stator windings of the generator forms the subject of separate studies on the fact that the shape of these curves is influenced by other factors which are not sufficiently thoroughly studied yet but from already existing research results it is known that they change the harmonic spectrum of phase voltages of the generator.

To determine the extreme limit of the operating range of the positive slip zone of the asynchronized generator with contactless valve system, it is necessary to have information on the nature of the currents of the rotor winding of the generator for other larger values of slip. Therefore, below we give the calculating dependence of these currents for a series of values of positive slip. The shape of these curves will provide information for understanding the laws of the flow of electromagnetic processes that occur in the contactless valve system of the asynchronized generator excitation and, as a result, will give a basis for the determination extreme allowable operating slip in its positive area.

Fig. 5 shows the calculated dependencies of the phase currents of the generator rotor winding for slip $\mathrm{S}=+0.5$.

From Fig. 5 it is seen that the curves of the phase currents of the rotor of the generator have a quasisinusoidal shape with a period of the fundamental harmonic equal to $0.04(T=0.04) \mathrm{s}$ corresponding to the slip frequency $F_{k}=25 \mathrm{~Hz} \quad\left(F_{k}=50 \cdot \mathrm{S}=50 \cdot 0.5=25\right)$. This shape of the curves of phase currents with a clearly defined frequency also ensures the stability of the generator voltage frequency, and therefore, for slip $\mathrm{S}=+0.5$, the CLVES of the ASG is operational.

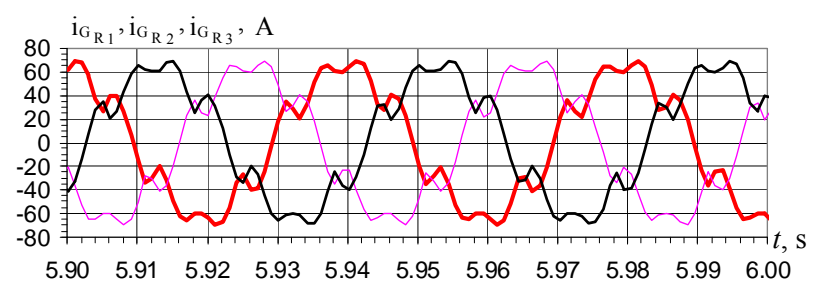

Fig. 5. ASG rotor phase currents $\mathrm{i}_{\mathrm{G}_{\mathrm{R} 1}}, \mathrm{i}_{\mathrm{G}_{\mathrm{R} 2}}, \mathrm{i}_{\mathrm{G}_{\mathrm{R} 3}}$

for $\operatorname{slip} \mathrm{S}=+0.5$

A further increase in slip in the positive region leads to a change in the shape of the curves of phase currents, as can be seen from Fig. 6 and Fig. 7. The first one depicts the calculated dependences of the phase currents of the rotor winding of the generator for slip $S=+0.9$, and on the second one - for $\operatorname{slip} \mathrm{S}=+0.95$. From these figures it is evident that phase currents in the shape are not sinusoidal. Instead, there is a tendency towards the formation of a voltage system of modulated shape, Therefore, the conclusion is unambiguous, its essence is that for a positive slip whose value exceeds $\mathrm{S}=+0.5$, CLVES of the ASG loses efficiency. Thus, the extreme limit of the positive range of the operating slip of the ASG is slip with the value $\mathrm{S}=+0.5$.

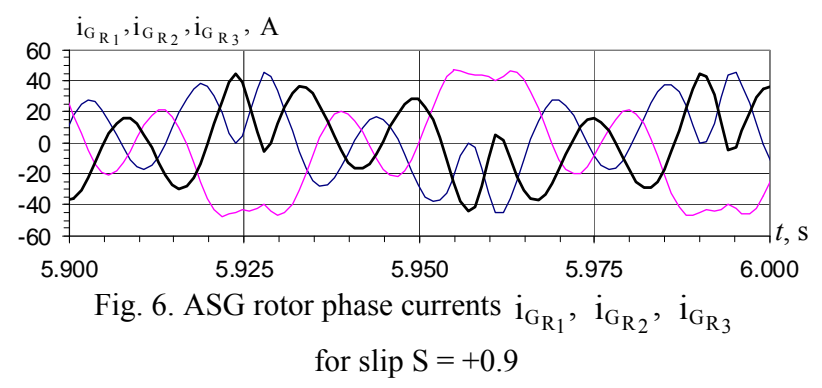




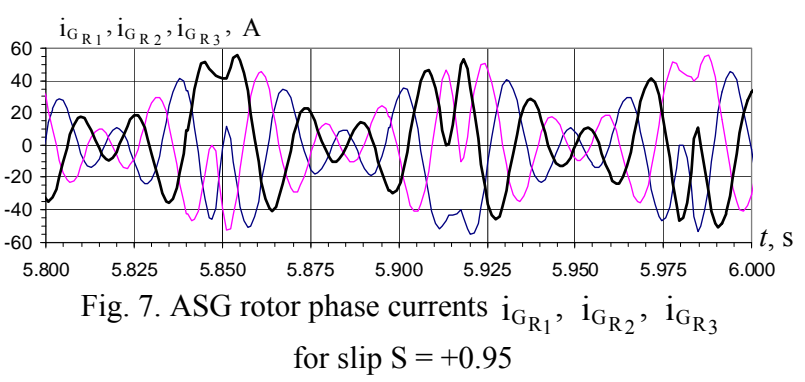

As already noted, the ASG with the CLVES on the basis of the cascade voltage modulator can operate in the mode of two-zone slip because the excitation here is executed from the side of the rotor, as in a synchronous machine. Therefore, it is fundamentally important to find out its functional possibilities for a negative slip range. To this end, research has also been carried out for a number of values of negative slip.

Fig. 8 depicts the calculated dependencies of phase currents of the rotor of the generator for the three values of slip: $\mathrm{S}=-0.2 ; \mathrm{S}=-0.8$ and $\mathrm{S}=-1.0$. From Fig. 8 it is clearly visible that the phase currents of the rotor of the ASG have a shape close to the sinusoid with the frequency of the fundamental harmonic which is equal to the slip frequency. This gives grounds to argue that unlike the positive area of slip, in the negative one the CLVES is operable in its entire range from $\mathrm{S}=0$ to $\mathrm{S}=-1.0$.
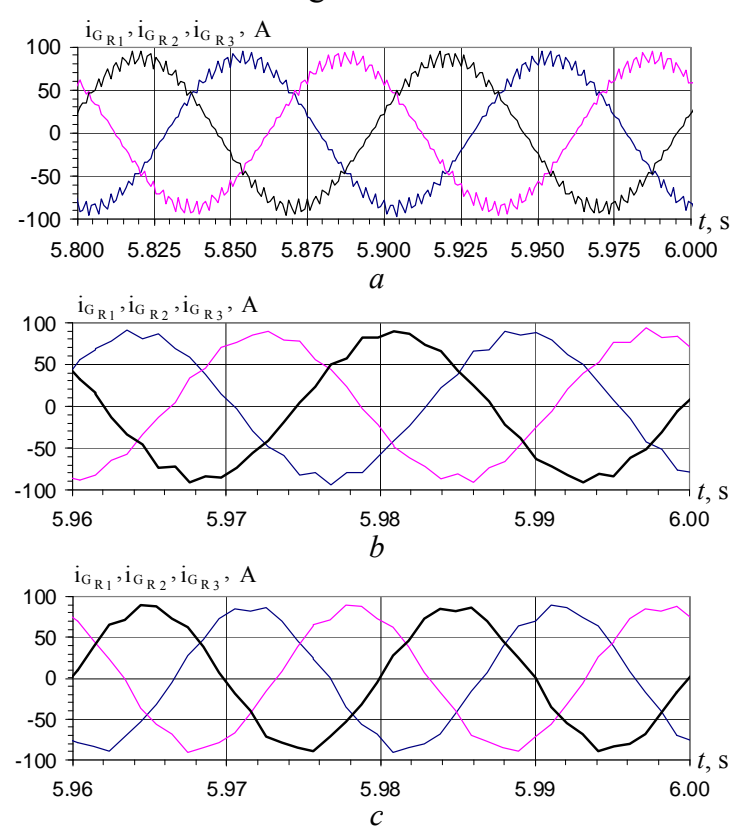

Fig. 8. ASG rotor phase currents $\mathrm{AC} \Gamma \mathrm{i}_{\mathrm{G}_{\mathrm{R}}}, \mathrm{i}_{\mathrm{G}_{\mathrm{R} 2}}, \mathrm{i}_{\mathrm{G}_{\mathrm{R} 3}}$

$$
(a-\text { for } \mathrm{S}=-0.2 ; b-\text { for } \mathrm{S}=-0.8 ; c-\text { for } \mathrm{S}=-1.0)
$$

At this stage, with the help of the mathematical model developed in [1] and the corresponding program code, an analysis of the electromagnetic processes is carried out in the contactless valve excitation system of the ASG on the basis of a cascade three-phase - three-phase voltage modulator according to the circuit of a single star and established the laws of their course on the effect of the two-zone slip on the performance of the asynchronized generator.

In the context of the prospect of research in order to further develop the theory of asynchronized generators of this type, it seems necessary to perform an analysis of the electromagnetic processes occurring in such generators for the effect of the two-zone slip on the voltage quality of the ASG and on the frequency criterion, and by the criterion of the harmonic spectrum. In addition, the goal is to carry out similar studies for a modulator circuit with a common connection of split phase phase branches of the rotors of the modular machines when the key $\mathrm{K}$ is locked (Fig. 1) because here the circuit is considered with a potential combined connection when the key $\mathrm{K}$ is open.

\section{Conclusions.}

1. The narrow range of operating dual-zone slip of an asynchronized generator with contactless valve excitation system based on a cascade voltage modulator under the circuit of a single star which at the time of recent research was \pm 0.06 does not allow the practical application of such generators as autonomous sources of electric power supply.

2. In order to study the possibilities of expanding the range of two-zone slip of the ASG with CLVES, the study of electromagnetic processes occurring in this excitation system was performed. Based on the research carried out by mathematical modeling with the help of the developed by the author mathematical models and software complex, the laws of the flow of these processes depending on the value of the two-zone slip are established.

3. By changing the parameters of the rotors of the machines of the modulator and ASG due to an increase in the ratio of the number of turns of the stator winding to the winding of the rotor of the asynchronous machines of the modulator and the generator, an essentially expansion of the slip range of the asynchronized generator was achieved.

4. The area of negative slip is increased to the value $\mathrm{S}=-1$, and the area of the positive one up to $\mathrm{S}=+0.5$.

5. Extension of the range of working slip to the specified limits creates real opportunities for the practical application of generators of this class in autonomous power supply systems with a wide range of changes in the rotational speed of the drive.

\section{REFERENCES}

1. Vasyliv K.M. Mathematical model of dynamic processes of an autonomous electric power system on the basis of contactless asynchronized generator with a three-phase-three-phase cascade modulated exciter. Technical electrodynamics, 2004, no.5, pp. 50-55. (Ukr).

2. Vasyliv K.M. Regularities of electromagnetic processes in the contactless excitation system of an asynchronous generator following a two-star scheme based on a threephase-threephase voltage modulator. Bulletin of NTU «KhPI», 2016, no.32(1204), pp. 48-52. (Ukr).

3. Galinovskiy A.M. Non-contact asynchronized generator with a modulated frequency converter. Trudy I Mezhdunarodnoi (III Vserossiiskoi) konferentsii po Elektromekhanotronike [Proceedings of the 1st International (III All-Russian) Conference on Electromechanotronics]. St. Petersburg, 1997, pp. 182-192. (Rus).

Received 25.02.2018

K.M. Vasyliv, Doctor of Technical Science, Professor,

Lviv Polytechnic National University,

28a, S. Bandera Str., Lviv, 79013, Ukraine,

phone +380322226403 ,

e-mail: karl.vasyliv@gmail.com

How to cite this article:

Vasyliv K.M. Regularities of electromagnetic processes of a contactless excitation system of an asynchronized generator based on a cascade three-phase-three-phase voltage modulator in a single-star circuit. Electrical engineering \& electromechanics, 2018, no.3, pp. 17-22. doi: 10.20998/2074-272X.2018.3.02. 